\title{
TEATRO ESPAÑOL \\ EN LOS ESCENARIOS DE PARÍS (2014-2015) ${ }^{1}$
}

THE SPANISH THEATRE ON PARIS STAGE (2014-2015)

\author{
Michel GOMES \\ SELITEN@T \\ gomesm3@yahoo.es
}

Resumen: Desde hace siglos, la ciudad de París es considerada como uno de los centros más importantes del teatro europeo. La gran cantidad de escenarios que dispone la Ciudad Luz atrae autores, directores de escena y compañías del mundo entero. Este estudio analiza la presencia de las obras y compañías españolas en la capital francesa, durante los años 2014 y 2015, con el objetivo de examinar qué obras se exportan y qué miembros del teatro español visitan los escenarios extranjeros dentro de la realidad contemporánea europea.

Palabras claves: Teatro. Español. París. Francia. 2014-2015.

Abstract: For centuries, Paris has been considered one of the most important theatre stage in Europe. The great number of theatres in the so-called City of Light, appeals to authors, stage managers and theatre companies from all over the world. The present study aims to analyse the Spanish works and companies in the French capital in 2014 and 2015 in order to examine which members of the Spanish theatre visit foreign stages in today's Europe.

Key Words: Theatre. Spanish. Paris. France. 2014-2015.

1 Este trabajo se inserta dentro de las actividades teatrales del SELITEN@T, el Centro de Investigación de Semiótica Literaria, Teatral y Nuevas Tecnologías, dirigido por el profesor José Romera Castillo, cuyas actividades pueden verse en http://www.uned.es/centro-investigacion-SELITEN@T, además de diversos trabajos suyos como "Teatro en escena: un centro de investigación sobre la vida teatral en España" (José Romera Castillo, 2012a) además de uno de sus libros "Romera Castillo, 2011). "Estudio del teatro en la primera década del siglo XXI en el SELITEN@T" (Romera Castillo, 2012b). 


\section{INTRODUCCIÓN}

Analizar la presencia del teatro de un país en otro siempre ha sido un ejercicio muy interesante para conocer las tendencias teatrales tanto del lugar de origen como del lugar de destino. Así, observar que un autor, un director de escena o una compañía exporta su trabajo, significa que este gusta y que no solamente puede ser destinado a una asistencia local, sino también a un público extranjero modificando o no unos aspectos de las obras o puestas en escena. También podemos afirmar que analizar la exportación del teatro de un país permite medir su dinamismo teatral considerando que cuantas más obras se crean en este, más probabilidades existen de que algunas se representen en países extranjeros. De la misma manera, es posible deducir que observar la presencia de un teatro de un país en otro es señal de un teatro de calidad ya que, de forma general, los espectáculos se estrenaron con éxito en el país de origen antes de viajar al extranjero. Por fin, analizar la presencia del teatro de un país europeo en otro del viejo continente, puede ser muy útil para observar el estado de la construcción europea a nivel cultural. En efecto, se habla muy a menudo en los medios de comunicación del estado de evolución de esa construcción a nivel político o económico y poco a nivel cultural. Pocas veces los ciudadanos tienen acceso a la información sobre si las instituciones europeas fomentan o no los contactos teatrales facilitando la movilidad (con el espacio Schengen por ejemplo) y los intercambios de obras y compañías creando "una europeización" del mundo teatral o si esos intercambios se realizan únicamente a través de iniciativas individuales o estatales como ocurrió en Europa desde la Edad Media permitiendo las influencias teatrales entre países. Para estudiar esas cuestiones en relación con el teatro español, nos proponemos realizar un estudio de la presencia del teatro español en los escenarios de París en el marco de los estudios del SELITEN@T sobre la presencia del teatro español en el extranjero².

2 Pueden consultarse los estudios sobre teatro del SELITEN@T en: $h t t p: / / w w w 2 . u n e d$. es/centro-investigacion-SELITEN@T/estudios_sobre_teatro.html [06/04/2016]. Dentro de los estudios sobre el teatro español en el extranjero podemos citar las tesis doctorales siguientes:

-GARCÍA RODRÍGUEZ, Coral, La vida escénica del teatro español del siglo XX en Italia (1960-1998) (defendida en la UNED en diciembre de 1999). Puede consultarse una parte de esta tesis en Teatro español en Italia: Valle-Inclán, García Lorca, Sastre y Arrabal (Florencia: Alinea, 2003).

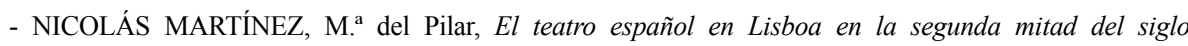
XIX (defendida en la UNED en enero de 2016): http://www2.uned.es/centro-investigacion-SELITEN@T/pdf/ Teatro_espanol_Lisboa_1850-1899.pdf [06/04/2016].

- COATES, John Benjamin, El teatro representado en español en Los Ángeles durante los años 2000-2010(UNED,2012:http://www2.uned.es/centro-investigacion-SELITEN@T/pdf/John_B_Coates.pdf [06/04/2016]. 
La elección de Francia para estudiar el teatro español puede considerarse interesante al tratarse de un país vecino. En efecto, el hecho de que esos dos países tengan una frontera en común puede representar un factor que facilita los intercambios, ya que, para la población francesa, España y su cultura no es un mundo desconocido. Además, hay que recordar que Francia y España poseen una larga historia teatral en común llena de influencias provenientes de ambos países. Como ejemplo de influencia de la comedia española en obras francesas, podemos citar a de Pierre Corneille cuya obra maestra El Cid fue inspirada en la comedia Las mocedades del Cid de Guillén de Castro (Picciola, 2002) o la inspiración que este tomó en Juan Ruiz de Alarcón y Mendoza para su obra El mentiroso (Chasles, reimpresión 1973). Otro ejemplo emblemático de esa influencia transpirenaica es la de Molière que se inspiró en ciertos apectos de Tirso de Molina y de Lope de Vega para sus comedias Don Juan y L'école des femmes respectivamente (Martinenche, 1906). La comedia española representó durante varios siglos una fuente de inspiración para muchos autores franceses de géneros literarios diferentes incluyendo, además de los dramaturgos previamente citados, las comedias y novelas de François de Métel de Boisrobert, la novela picaresca de Alain-René-Lesage, el teatro romántico de Hippolyte Lucas o la adaptación de La devoción de la cruz de Calderón de la Barca por Albert Camus (Couderc, 2012). Tras la elección de Francia como país de estudio, centrarnos en la Ciudad luz parece totalmente lógico por ser la capital de un país muy centralizado. También la ciudad de París, a partir del reinado del rey Luis XIV, se convirtió en una ciudad del espectáculo donde el sector teatral ocupa todavía un lugar muy importante en la vida cultural y económica. Incluso, en períodos de caída de la asistencia a los teatros, el ayuntamiento suele lanzar campañas para estimular el sector como fue el caso en 1995 cuando "durante el mes de diciembre, lanzó una campaña que consistía en regalar una entrada a quien adquiriera una localidad" (Toquero, 2002, 111).

La mayoría de las decisiones culturales que conciernen a todo el territorio francés provienen de París que se considera entonces como el pulmón del mundo teatral francés. Las cifras lo demuestran: la capital francesa cuenta con el $25 \%$ de las compañías francesas (Ministère de la Culture et de la Communication, 2013) y se contabilizan alrededor de ciento setenta escenarios (Wallon, 2010). Incluso se contabilizan más de trescientos lugares de representación añadiéndole a la capital sus afueras (lo que se llama "La grande Couronne"). Esas cifras demuestran que la ciudad de París ocupa un puesto muy importante no solamente en Francia, sino también en el espacio europeo y mundial, ya que tener un gran número de escenarios puede atraer a autores o compañías del mundo entero, incluyendo lo proveniente de España.

Si queremos estudiar las tendencias actuales de la presencia del teatro español en París, la elección del período que abarca los años 2014 y 2015 nos parece interesante para analizar qué se exporta últimamente del teatro español y qué tendencias gustan 
al público francés. De esta forma, podríamos observar si al público galo solamente le interesan los grandes nombres del teatro español del pasado (obras y autores del Siglo de Oro, de los siglos XIX o XX) o si las generaciones contemporáneas exportan al Hexágono sus trabajos y si viajan a París para colaborar con los teatros franceses.

\section{RELACIÓN CRONOLÓGICA DE LAS OBRAS ESPAÑOLAS REPRESENTADAS EN PARÍS (2014-2015)}

Para una mejor visibilidad, presento la relación de la presencia del teatro español en París cronológicamente y de la forma siguiente:

1.- Número entre paréntesis correspondiente a la posición de la función en la clasificación cronológica de las representaciones.

2.- La fecha de la primera representación (por ejemplo el 12/01 significaría que la primera representación tuvo lugar el día 12 de enero del año en que se encuentra).

3.- El título de la obra seguido de su título original en español.

4.- El autor de la obra (obra de, inspirada en, adaptación de...).

5.- Los datos técnicos: puesta en escena, compañía.

6.- Las fechas y horas de representación: el número de representaciones (si está disponible) y el idioma de la función si no es el francés.

7.- El lugar de la representación.

\section{AÑO 2014}

(01) 07/02: La Maison de Bernarda Alba (La casa de Bernarda Alba), drama de Federico García Lorca. Adaptación de Mani Muller. Puesta en escena de Carole Lorang. Compañía Le Grand Boube. Siete representaciones a las 20:30 h. entre el 7 y el 15 de febrero. Théâtre des Bouffes du Nord ${ }^{3}$.

(02) 03/03: Jardinage Humain adaptación de Jardinería Humana, de Rodrigo García. Puesta en escena de Patrick Piard. Compañía Graine de Soleil. Una representación el día 3 de marzo a las 19 h. en el marco del festival Au Féminin 2014. Théâtre de Verre4.

(03) 08/04: Noces de sang, adaptación del drama Bodas de sangre de Federico García Lorca. Puesta en escena de Rubia Matignon. Compañía Les P'tits Barlous. Tres representaciones los 08 y 09 de abril y el 11 de junio respectivamente a las 20:30 h y 20h. Théâtre de Ménilmontant.

3 Dossier de prensa del espectáculo disponible en esta dirección: http://www.bouffesdunord.com/fr/ download/press-spectacles/52ebbce65d7f2/0 [27/03/2016].

4 Puede consultarse la programación del festival Au Féminin 2014 en esta dirección: http://www. mesillusionscomiques.com/media/01/02/2707493455.pdf[27/03/2016]. 
(04) 30/04: Ignatius, des idiots et des fous, de Chantal Mélior. Espectáculo inspirado en Miguel de Cervantes (entre otros autores extranjeros). Puesta en escena de la autora. Compañía Le Théâtre du Voyageur. Quince representaciones entre el 30 abril y el 15 de junio, del miércoles al sábado, a las $20 \mathrm{~h}$. y los domingos a las 15:30 h. Théâtre du Soleil 5 .

(05) 27/05: Belgrade, adaptación de Belgrado, de Angélica Liddell. Puesta en escena de Thierry Jolivet. Compañía La Meute. Dos representaciones los días 27 y 28 de mayo respectivamente a las 20:30 h. y 19:30 h. Théâtre Centquatre ${ }^{6}$.

(06) 26/05: Solfatara, comedia de Mónica Almirall, Miquel Segovia y Albert Pérez Hidalgo. Puesta en escena de los autores. Compañía Atresbandes. Dos representaciones los dias 26 y 27 de mayo a las 2030 h. Festival Impatience 2014. Théâtre du Rond-Point ${ }^{7}$.

(07) 02/06: Caprices, de José Drevon. Espectáculo inspirado en Francisco de Goya. Puesta en escena de Guillaume Dujardin. Compañía Mala Noche. Veinte representaciones entre el 02 y el 24 de junio (a las 20:30 h. los lunes, martes, miércoles y viernes; a las 19 h. los jueves y sábados). Théâtre de l'Atalante.

(08) 11/06: 35 minutes y La nuit électorale (35 minutos y La noche electoral), de Los Torreznos (Jaime Vallaure y Rafael Lamata). Puesta en escena de los autores. Compañía Los Torreznos. Una representación el 11 de junio a las 20 h. en el marco del festival Chantiers d'Europe. Théâtre de la Ville ${ }^{8}$.

(09) 16/06: Materia Prima de Pablo Fidalgo. Puesta en escena de la compañía La Tristura. Una representación el 16 de junio a las 20:30 h en el marco del festival Chantiers d'Europe. Théâtre de la Ville?

(10) 23/06: Jeu et théorie du Duende, lectura dramatizada de la obra Juego y teoría del Duende, de Federico García Lorca. Lectura animada por Pierre Baux, el 23 de junio a las 19 h. Maison de la Poésie.

5 Puede consultarse la presentación del espectáculo en la página web del Théâtre du Soleil, incluyendo un fragmento de vídeo: http://www.theatre-du-soleil.fr/thsol/dans-nos-nefs/article/les-nomadesigniatius?lang=fr [27/03/2016].

6 Puede consultarse el dossier de prensa del festival Impatience 2014 en esta dirección: $h t t p: / / w w w$. theatredurondpoint.fr/wp-content/uploads/2015/06/dp-impatience6.pdf [27/03/2016].

7 Puede consultarse la presentación del espectáculo en la página web de la compañía Atresbandes, incluyendo un fragmento de vídeo: https://atresbandescast.wordpress.com/espectaculos/solfatara [27/03/2016].

8 Puede consultarse el programa del festival Chantiers d'Europe 2014 en vídeo en la cadena youtube del Théâtre de la ville en esta dirección: $h t t p s: / / w w w . y o u t u b e . c o m / w a t c h ? v=m \_8 v k y D 5 W H g$ [27/03/2016].

9 Puede consultarse la presentación del espectáculo en la página web de la compañía La Tristura: http://latristura.com/portfolio/materia-prima-2011-2 [27/03/2016]. 
(11) 28/06: Public Domain, de Roger Bernat. Puesta en escena del autor. Compañía La Mekánica. Una representación el 28 de junio a las 15 h. en el marco del festival Chantiers d'Europe. Théâtre de la Ville ${ }^{10}$.

(12) 05/07: Remarquables Utopies, espectáculo con un texto colectivo de Arrigo Barnabé, Felipe Ferraz, Isabel Ribeiro, José Ramón Fernández y Rui Frati. Puesta en escena de Rui Frati. Compañía del Théâtre de l'Opprimé. Once representaciones entre el 5 de julio y el 23 de noviembre. Festival Migractions. Théâtre de L'Opprimé ${ }^{11}$.

(13) 28/08: Yerma, drama rural de Federico García Lorca. Puesta en escena de Daniel San Pedro. Compañía La Compagnie des Petits Champs. Treinta y cuatro representaciones entre el 28 de agosto y el 5 de octubre (a las 19:30 h. los martes, jueves y sábados; 20:30 h. los miércoles y viernes y a las 15:30 h. los domingos). Théâtre 13 12 .

(14) 26/09: Don Quichotte ou le Vertige de Sancho, adaptación del Ingenioso hidalgo Don Quijote de la Mancha, de Miguel de Cervantes. Adaptación y puesta en escena de Régis Hébette. Compañía Public Chéri. Doce representaciones entre el 12 y el 27 de septiembre a las 20:30 h. o a las $17 \mathrm{~h}$. los domingos. Théâtre de L'Echangeur ${ }^{13}$.

(15) 16/10: Tout est silence, lectura dramatizada de la obra Todo es silencio, de Manuel Rivas. Lectura animada por Gustavo Guerrero, con una interpretación de Serge Mestre y programada el día 16 de octubre a las $19 \mathrm{~h}$. Maison de la Poésie ${ }^{14}$.

(16) 16/10: Pique-Nique en Campagne, adaptación de la obra Pic Nic en el campo de batalla, de Fernando Arrabal. Puesta en escena de Sotha. Compañía del Teatro Café de la Gare. Cincuenta y un representaciones entre el 16 de octubre 2014 y el 19 de junio 2015 (los miércoles y jueves a las 19 h. hasta enero de 2015 y los sábados a las 17:30 h. entre febrero y junio de 2015). Café de la Gare ${ }^{15}$.

(17) 21/11: Scènes pour une conversation après le visionnage d'un film de Michael

Haneke (Escenas para una conversación después del visionado de una película de

10 Puede consultarse la presentación del espectáculo en la página web del director: http://rogerbernat.info/ en-gira/domini-public [27/03/2016].

11 Puede consultarse la presentación del espectáculo en la página web del director de escena: $h t t p: / / w w w$. frati-ribeiro.com/?p=2371\&lang=fr [27/03/2016].

12 Puede visionarse una presentación vídeo del espectáculo en esta dirección: http://www.theatre13.com/ saison/spectacle/yerma/presentation-video--3 [27/03/2016].

13 Puede consultarse el dossier de prensa del espectáculo en la siguiente dirección: $h t t p: / / w w w . l e c h a n g e u r$. org/wp2/wp-content/uploads/2014/05/Dossier_Don_QuichottJOH.pdf [27/03/2016].

14 Puede visionarse un fragmento de la presentación de Manuel Rivas de su obra en el Instituto Cervantes de París en octubre 2014. El vídeo está disponible en la cadena de YouTube de España en París: https://www. youtube.com/watch?v=Bnod1tT4Aas [27/03/2016].

15 Puede visionarse el tráiler del espectáculo en esta dirección: http://www.ticketac.com/spectacles/piquenique-en-campagne.htm [27/03/2016]. 
Michael Haneke), de Pablo Albert. Puesta en escena de Céleste Germe. Compañía Das Plateau. Una representación el 21 de noviembre a las 20:30 h. Théâtre ouvert ${ }^{16}$.

(18) 23/11: Todo dice que sí..., lectura dramatizada de poesías de Pedro Salinas, Luis Cernuda, Juan Ramón Jiménez, Gabriel Celaya, Jaime Gil de Biedma, José Agustín Goytisolo, Josep María Fonollosa y Ángel González. Puesta en escena de Alberto San Juan. Una representación en español sin subtítulos el 23 de noviembre a las $17 \mathrm{~h}$. en el marco del festival Don Quijote 2014. Café de la Danse ${ }^{17}$.

(19) 23/11: Auto retrato de un joven capitalista español, monólogo de Alberto San Juan. Puesta en escena del autor. Una representación en español sin subtítulos el día 23 de noviembre a las 19 h. en el marco del festival Don Quijote 2014. Café de la Danse.

(20) 25/11: Fuenteovejuna. Breve tratado sobre las ovejas domésticas, de Lope de Vega. Adaptación y puesta en escena de Anna María Ricart. Compañía Obskené. Una representación en español sin subtítulos el día 25 de noviembre a las 20:30 h. en el marco del festival Don Quijote 2014. Café de la Danse ${ }^{18}$.

(21) 26/11: Penal de Ocaña, de María Josefa Canellada. Adaptación y puesta en escena de Ana Zamora. Compañía Nao d'Amores. Una representación en español sobretitulada en francés el día 26 de noviembre a las 20:30 h. en el marco del festival Don Quijote 2014. Café de la Danse ${ }^{19}$.

(22) 27/11: Clásicos cómicos, entremeses de burlas: El niño de la Rollona de Francisco de Avellaneda, Guardadme las espadas de Calderón de la Barca, Los muertos vivos de Luis Quiñones de Benavente, Los toros de Alcalá de Juan de la Hoz y Mota y Los Locos, una obra anónima. Puesta en escena de Jesús Peña. Compañía Teatro Corsario. Una representación en español sin subtítulos el día 27 de noviembre a las 20:30 h. en el marco del festival Don Quijote 2014. Café de la Danse ${ }^{20}$.

(23) 03/12: You are my destiny (Lo stupro di Lucrezia), tragedia de Angélica Liddell. Puesta en escena de la autora. Compañía Atra Bilis Teatro. Once representaciones en

16 Puede consultarse la presentación del espectáculo en la página web de la compañía Das Plateau: http:// www.dasplateau.net/2015/02/2014-scenes-pour-une-conversation-apres-le-visionnage-d-un-film-demichael-haneke-pablo-gisbert.html [28/03/2016].

17 Puede consultarse la programación de la edición del 2014 del festival Don Quijote en la página web enteramente dedicada de esa vigésima tercera edición del festival: http://festivaldonquijote.fr/festival2014/ accueilfestival2014.html [28/03/2016].

18 El dossier de prensa del espectáculo está disponible en esta dirección: $h t t p: / / m e d i a . w i x . c o m / u g d / b d 7440$ c0b8d34a6eb2486eb093d41e0c4df333.pdf [28/03/2016].

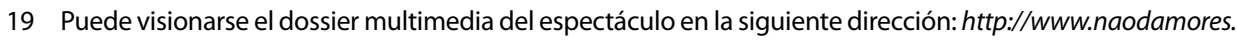
com/marcos/DossierPenal/DossierMultimedia.html [28/03/2016].

20 Puede visionarse la presentación del espectáculo en la cadena de la compañía Teatro Corsario en YouTube: https://www.youtube.com/channel/UCpCcCXBP4XKOJ6IK-xW8khA [28/03/2016]. 
español e italiano entre el 03 y el 14 de diciembre. Espectáculo que entraba en la programación del Festival d'automne de París. Théâtre de l'Odéon ${ }^{21}$.

(24) 04/12: Don Quichotte, adaptación del Ingenioso hidalgo Don Quijote de la Mancha, de Miguel de Cervantes, por Laurent Rogero (y puesta en escena). Compañía Anamorphose. Una representación el día 4 de diciembre a las $19 \mathrm{~h}$. Théâtre de L'Agora.

(25) 04/12: Del Lazarillo de Tormes, de Jaime Santos. Puesta en escena del autor. Compañía La Chana. Una representación en español sin subtítulos el día 4 de diciembre a las 20:30 h. en el marco del festival Don Quijote 2014. Espace Beaujon.

(26) 06/12: El Régimen del pienso, de Eusebio Calonge. Puesta en escena de Paco de la Zaranda. Compañía La Zaranda. Una representación en español sobretitulada en francés estaba prevista el día 6 de diciembre a las 20:30 h. Sin embargo, este espectáculo programado para el festival Don Quijote 2014 fue cancelado. Café de la Danse ${ }^{22}$.

(27) 17/12: El retablillo de Don Cristóbal, farsa para títeres y bufones adaptada de la obra de Federico García Lorca. Puesta en escena de Luis F. Jiménez. Compañía Ditirambo. Cuatro representaciones en español sobretituladas en francés del 17 al 20 de diciembre (a las 19:30 h. o 20:30 h.) en el marco del festival Don Quijote. Théâtre 13.

(28) 17/12: El corral de Bernarda, tragicomedia bufonesca inspirada en La casa de Bernarda Alba de Federico García Lorca y de Ernesto Caballero. Puesta en escena de Luis F. Jiménez. Compañía Ditirambo. Cuatro representaciones en español sobretituladas del 17 al 20 de diciembre (a las 19:30 h. o 20:30 h.). Espectáculo que entraba en la programación del festival Don Quijote 2014 y que se representaba junto con el espectáculo El retablillo de Cristóbal del mismo director. Théâtre 13.

\subsection{AÑO 2015}

(29) 14/01: Amour de Don Perlimplin avec Bélise en son jardin, adaptación para títeres de la tragicomedia Amor de don Perlimplín con Belisa en su jardín, de Federico García Lorca. Puesta en escena de Dolores Lago Azqueta. Compañía Les Oiseaux Migrants. Una representación el 14 de enero a las $20 \mathrm{~h}$. Théâtre Vingtième ${ }^{23}$.

(30) 15/01: L'avantage avec les animaux c'est qu'ils t'aiment sans poser de questions, (Lo bueno de los animales es que te quieren sin preguntar nada) de Rodrigo García. Puesta

21 Puede consultarse el dossier de prensa del espectáculo en: $h t t p: / / w w w . t h e a t r e-o d e o n . e u / s i t e s / d e f a u l t / f i l e s /$ dp_you_are_my_destiny.pdf[28/03/2016].

22 Puede consultarse la página web oficial del espectáculo en esta dirección: $h$ ttp://elregimendelpienso. blogspot.com.es [28/03/2016].

23 Puede consultarse el dossier de prensa del espectáculo en esta dirección: $h t t p: / / w w w . e p e e d e b o i s . c o m / w p-$ content/uploads/2015/04/Perlimplin115.pdf [28/03/2016]. 
en escena de Christophe Perton. Compañía Scènes \& Cités. Veintiséis representaciones del 15 de enero al 14 de febrero a las 20:30h. Théâtre du Rond-Point ${ }^{24}$.

(31) 06/02: Le grand voyage, adaptación de la obra El largo viaje, de Jorge Semprún por Pascal y Vincent Reverte. Puesta en escena de los autores. Compañía Le Tour du Cadran. Tres representaciones a las 20:30 h. y 16 h. entre el 6 y el 8 de febrero. Théâtre de l'Ouest Parisien ${ }^{25}$.

(32) 07/02: L'idée ridicule de ne plus jamais te revoir, lectura dramatizada de la obra La ridícula idea de no volver a verte, de Rosa Montero. Espectáculo animado por Kerenn Elkaïm e interpretado por Pascale Fougère. Lectura realizada el día 7 de febrero a las 19 h. Maison de la Poésie ${ }^{26}$.

(33) 03/03: La discrète amoureuse, adaptación de la comedia La discreta enamorada, de Lope de Vega. Adaptación de Benjamin Penamaria y de Justine Heynemann. Puesta en escena de Justine Heynemann. Compañía Soy Création. Treinta y seis representaciones entre el 03/03 y el 12/04 (a las 19:30 h. los martes, jueves y sábados; a las 20:30 h. los miércoles y viernes y a las 15:30 h. los domingos). Théâtre $13^{27}$.

(34) 04/03: Daisy, de Rodrigo García. Puesta en escena del autor. Compañías Bonlieu y La Carnicería Teatro. Cinco representaciones en español sobretituladas entre el 4 y el 8 de marzo a las 20:30 h. Théâtre du Rond-Point ${ }^{28}$.

(35) 29/03: Elise ou la vraie vie, texto de Claire Etcherelli, adaptado por Eva Castro. Puesta en escena de Castro. Compañía Ginkgo Biloba. Veinticuatro representaciones entre el 29 de marzo y el 6 de mayo a las 19 h. 021 h. Manufacture des Abbesses ${ }^{29}$.

(36) 14/04: Don Juan, amère Mémoire de moi, de Miguel Gallardo y Paco Bernal. Espectáculo de títeres adaptado de Tirso de Molina, José Zorrilla, Molière y Josep Palau i Fabre. Puesta en escena de María Castillo. Compañía Pelmânec. Seis representaciones entre el 14 y el 19 de abril (a las 19:30 h. el martes, jueves y sábado, a las 20:30 h el miércoles y viernes y a las 15:30 h. los domingos). Théâtre 13.

24 Puede consultarse su dossier de prensa en esta dirección: http://www.theatredurondpoint.fr/wp-content/ uploads/2015/06/lavantage_avec_les_animaux.pdf[28/03/2016].

25 Puede consultarse una entrevista en vídeo de Pascal Reverte sobre su espectáculo en esta dirección: $h t t p: / /$ www.theatre-video.net/video/Le-Grand-Voyage [28/03/2016].

26 Puede escucharse el podcast del programa L'humeur Vagabonde del día 4 de febrero 2015 de la radio France Inter con Rosa Montero como invitada y, en el cual la autora habla de su obra y del evento de la Maison de la Poésie: $h t t p: / / w w w . f r a n c e i n t e r . f r / p l a y e r / r e e c o u t e r ? p l a y=1043407$ [28/03/2016].

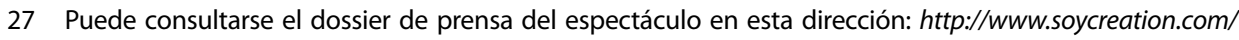
wp-content/uploads/2014/10/discrete-juin-2014.pdf [28/03/2016].

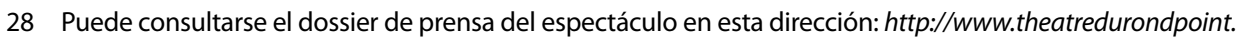
$\mathrm{fr} /$ wp-content/uploads/2015/06/daisy.pdf [28/03/2016].

29 Puede escucharse el podcast del programa Reportages VIP de la radio VIP con Eva Castro como invitada,

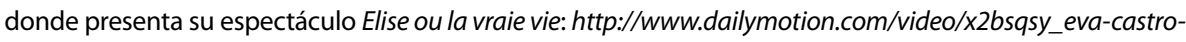
elise-ou-la-vraie-vie_creation [28/03/2016]. 
(37) 23/04: La Maison de Bernalda Alba, drama de Federico García Lorca. Puesta en escena de Lilo Baur. Compañía de La Comédie Française. Cincuenta y cinco representaciones del 23 de abril al 30 de diciembre. La Comédie Française ${ }^{30}$.

(38) 05/05: A house in Asia, de Álex Serrano y Pau Palacios. Puesta en escena de Serrano. Compañía Agrupación Sr Serrano. Dos representaciones en inglés, sobretituladas en francés, los días 5 y 6 de mayo a las 19:30 h. Representada en el marco del $8^{\mathrm{e}}$ Biennale Internationale des Arts de la Marionnette. Maison des Métallos ${ }^{31}$.

(39) 06/05: Ça aussi ça passera, lectura dramatizada de la obra También esto pasará, de Milena Busquets. Lectura animada e interpretada por Sophie Joubert, el día 6 de mayo a las 19:30 h. Maison de la Poésie ${ }^{32}$.

(40) 07/05: Les amours de Don Perlimplin avec Bélise en son jardin, fantasía tragicobufonesca adaptada de Amor de Don Perlimplín con Belisa en su jardín, de Federico Garcia Lorca. Adaptación y puesta en escena de Hervé Petit. Compañía La Traverse. Dieciocho representaciones entre el 7 y el 24 de mayo (los jueves y viernes a las $16 \mathrm{~h}$. los sábados a las 16 h. y 19 h. y los domingos a las 18 h. Sesiones escolares los días 8 , 15 y 22 de mayo a las 14:30 h.). Théâtre de l'Epée de Bois ${ }^{33}$.

(41) 07/05: La maison de Bernalda Alba, adaptación del drama La casa de Bernarda Alba, de Federico García Lorca. Puesta en escena de Hervé Petit. Compañía La Traverse. Doce representaciones entre el 7 y el 24 de mayo (del jueves al sábado a las 20:30 h. los domingos a las $16 \mathrm{~h}$. y sesiones para escolares los jueves y viernes por la mañana). Théâtre de l'Epée de Bois.

(42) 06/10: Alba, adaptación de La casa de Bernada Alba, de Federico García Lorca. Puesta en escena de Yves Marc. Compañía Théâtre du Mouvement. Una representación el 6 de octubre a las $20 \mathrm{~h}$. Théâtre Vingtième.

(43) 20/10: Notes de cuisine, adaptación de Notas de cocina, de Rodrigo García. Puesta en escena de Jean-luc Vincent. Compañía Les Roches Blanches. Ocho representaciones entre el 20 y el 30 de octubre a las $19 \mathrm{~h}$. Théâtre de la $\operatorname{Loge}^{34}$.

(44) 10/11: Primera carta de San Pablo a los Corintios. Cantata BWV4, Christ lag in Todesbanden. Oh, Charles! de Angélica Liddell. Puesta en escena de la autora.

30 Puede consultarse el dossier de prensa del espectáculo en esta dirección: http://www.comedie-francaise.fr/images/telechargements/programme_bernardaalba1415.pdf [28/03/2016].

31 Puede visionarse un vídeo de presentación del espectáculo en esta dirección: http://www. maisondesmetallos.org/2015/03/10/a-house-asia [30/03/2016].

32 Puede visionarse una presentación en francés de la obra por su autora Milena Busquets en esta dirección: https://www.youtube.com/watch?v=nOeqidJ8sOw [30/03/2016].

33 Puede consultarse el dossier de prensa del espectáculo en esta dirección: $h t t p: / / w w w . e p e e d e b o i s . c o m / w p-$ content/uploads/2015/01/DossierDiffusion3.pdf [30/03/2016].

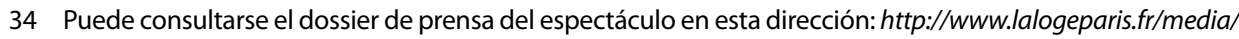
event/s11/id1011/dossier-notes-de-c.-oct-2015.pdf[30/03/2016]. 
Compañía Atra Bilis Teatro. Siete representaciones en español y sueco sobretituladas en francés entre el 10 y el 15 de noviembre (a las $20 \mathrm{~h}$. de martes a viernes, a las 15 h. y 20 h. los sábados y a las 15 h. el domingo). Espectáculo que entraba en la programación del festival d'Automne. Théâtre de l'Odéon-Théâtre de L'Europe ${ }^{35}$.

(45) 12/11: 4 de Rodrigo García. Puesta en escena del autor. Compañía HTH (ex Carnicería). Diez representaciones en español sobretituladas en francés entre el 12 y el 22 de noviembre (todos los días a las 20:30 h. los jueves a las 19:30 h. y los domingos a las 15 h.) en el marco del festival d'Automne. Théâtre Nanterre-Les Amandiers ${ }^{36}$.

(46) 21/11: Famélica, comedia de Juan Mayorga. Puesta en escena de Jorge Sánchez. Compañía La Cantera. Una representación en español sobretitulada en francés el 21 de noviembre a las 20:30 h en el marco del festival Don Quijote. Café de la Danse. Cancelado por medidas de seguridad tras los atentados del 13 de noviembre de $2015^{37}$.

(47) 23/11: Juana, la reina que no quiso reinar, drama de Jesús Carazo. Puesta en escena de Juan Dolores. Compañía Histrión Teatro. Una representación en español sobretitulada en francés el 23 de noviembre a las 20:30 h. en el marco del festival Don Quijote. Café de la danse. Función cancelada por medidas de seguridad ${ }^{38}$.

(48) 24/11: Scènes pour une conversation après le visionnage d'un film de Michael

Haneke (Escenas para una conversación después del visionado de una película de Michael Haneke), de Pablo Albert. Puesta en escena por la compañía el Conde de Torrefield. Cinco representaciones en español sobretituladas en francés entre el 24 y el 28 de noviembre a las $21 \mathrm{~h}$. Théâtre Bastille ${ }^{39}$.

(49) 24/11: Ligeros de equipaje, drama de Jesús Arbués. Puesta en escena del autor. Compañía Viridiana. Dos representaciones en español sobretituladas en francés los días 24 y 25 de noviembre a las 20:30 h. en el marco del festival Don Quijote. Café de la danse. Función cancelada por medidas de seguridad.

(50) 24/11: Una niña, espectáculo para niños adaptado de Grassa Toro. Adaptación y puesta en escena de Rosa Díaz. Compañía La Rous Teatro. Una representación en

35 Puede visionarse un fragmento del espectáculo en la siguiente dirección: $h t t p: / / w w w . t h e a t r e-v i d e o . n e t /$ video/Primera-carta-de-San-Pablo-a-los-Corintios-extrait [30/03/2016].

36 Puede consultarse el dossier de prensa de 4 de Rodrigo García en esta dirección: http://www.festivalautomne.com/uploads/spectacle/Rodrigo_Garcia6.pdf[30/03/2016].

37 Puede consultarse el programa del festival Don Quijote 2015 emitido por la Embajada de España en Francia:http://www.exteriores.gob.es/Embajadas/PARIS/fr/Embajada/InfoCulturelle/Documents/ NEWSLETTER\%202015-\%2011\%20-\%2011.pdf [30/03/2016].

38 Puede consultarse el vídeo de presentación del festival Don Quijote 2015 en la cadena de Youtube del Grupo Zorongo: $h$ ttps://www.youtube.com/watch?v=V4AYXolhMPO\&feature=youtu.be [30/03/2016].

39 Puede consultarse el dossier de prensa del espectáculo en la siguiente dirección: $h t t p: / / w w w . t h e a t r e-$ bastille.com/media/bastille/8-dossier_fr.pdf[30/03/2016]. 
colaboración con el Instituto Español García Lorca, el día 24 de noviembre a las 14 h. Festival Don Quijote. Café de la danse. Función cancelada por medidas de seguridad.

(51) 26/11: La Celestina, tragicomedia de Fernando de Rojas. Puesta en escena de Ricardo Iniesta. Compañía Atalaya. Una representación en español sin subtítulos el 26 de noviembre a las 20:30 h. en el marco del festival Don Quijote. Café de la danse. Función cancelada por medidas de seguridad.

(52) 27/11: Només són dones, de Carmen Domingo. Puesta en escena de Carme Portaceli. Compañía Factoría Escénica Internacional. Una representación en catalán sobretitulada en francés el 27 de noviembre a las 20:30 h. En el marco del festival Don Quijote. Café de la danse. Función cancelada por medidas de seguridad.

(53) 07/12: Et les poissons partirent combattre les hommes, adaptación del drama $Y$ salieron los peces a combatir contra los hombres, de Angélica Liddell. Puesta en escena de Anne-Frédérique Bourget. Compañía Maskantête. Una representación el día 7 de diciembre a las $20 \mathrm{~h}$. Théâtre Jean Dame ${ }^{40}$.

(54) 17/12: Coûte que coûte, de Roser Montilló Guberna, Elisabeth Gonçalves y Brigitte Seth. Puesta en escena de las autoras. Compañía Toujours Après Minuit. Siete representaciones entre el 17 y el 25 de diciembre a las 19:45 h. 20:45 h. o 17:15 h. según los días. Théâtre National Chaillot ${ }^{41}$.

\section{CONCLUSIONES}

Como podemos observar en la relación de las representaciones, obtenemos un total de 54 programaciones de espectáculos relacionados con el teatro español: 28 lo fueron en el 2014 y 26 en el 2015, es decir, que existe una gran regularidad en la presencia española en los escenarios parisinos. Si comparamos el número 54 con la gran cantidad de lugares de representación que existen en la capital francesa puede parecer poco. Sin embargo, si tomamos en cuenta que la ciudad de París atrae espectáculos del mundo entero, podemos entender que el teatro español compite con otros. Además, hay que tomar en cuenta la lógica preferencia del público y de los teatros parisinos por programar el teatro francés, lo que puede limitar el espacio dedicado a los espectáculos extranjeros. Para entender mejor esa cifra y medir la importancia del teatro español en París, nos proponemos un breve estudio del contenido de los espectáculos.

40 Puede visionarse un fragmento de vídeo del espectáculo en esta dirección: $h$ ttps://vimeo.com/128895696 [30/03/2016].

41 Puede visionarse un fragmento del espectáculo en la cadena de Youtube del Théâtre National Chaillot: http://www.dailymotion.com/video/x2ta1/u [30/03/2016]. 


\subsection{ESPACIOS ESCÉNICOS}

Tabla 1. Los escenarios parisinos visitados por el teatro español en 2014-2015

\begin{tabular}{|c|c|c|c|}
\hline Nombre del escenario & $\begin{array}{l}\text { No total de re- } \\
\text { presentaciones } \\
\text { (No de } \\
\text { espectáculos } \\
\text { distintos) }\end{array}$ & Nombre del escenario & $\begin{array}{l}\text { No total de re- } \\
\text { presentaciones } \\
\text { ( No de } \\
\text { espectáculos } \\
\text { distintos) }\end{array}$ \\
\hline Le Théâtre 13 & $84(05)$ & Le Théâtre National Chaillot & $07(01)$ \\
\hline La Comédie Française & $55(01)$ & Le Théâtre Bastille & $05(01)$ \\
\hline Le Café de la Gare & $51(01)$ & La Maison de la Poésie & $04(04)$ \\
\hline Le Théâtre du Rond-Point & $33(03)$ & Le Théâtre de l'Ouest Parisien & $03(01)$ \\
\hline Le Théâtre de l'Epée de Bois & $30(02)$ & Le Théâtre de la Ville & $03(01)$ \\
\hline La Manufacture des Abbesses & $24(01)$ & Le Théâtre de Ménilmontant & $03(01)$ \\
\hline Le Théâtre de l'Atalante & $20(01)$ & Le Théâtre Centquatre & $02(01)$ \\
\hline Le Théâtre de L'Odéon & $18(02)$ & Le Théâtre Vingtième & $02(01)$ \\
\hline Le Théâtre du Soleil & $15(01)$ & La Maison des Métallos & $02(01)$ \\
\hline Le Café de la Danse & $13(12)$ & Le Théâtre de l'agora & $01(01)$ \\
\hline Le Théâtre de L'Echangeur & $12(01)$ & Le Théâtre de Verre & $01(01)$ \\
\hline Le Théâtre de l'Opprimé & $11(01)$ & Le Théâtre Ouvert & $01(01)$ \\
\hline LeThéâtre Nanterre- Amandiers & $10(01)$ & Le Théâtre La Loge & $01(01)$ \\
\hline LeThéâtre des Bouffes du Nord & $07(01)$ & L'Espace Beaujon & $01(01)$ \\
\hline
\end{tabular}

Como podemos observar en la tabla, las obras españolas estuvieron presentes en 28 escenarios distintos lo que representa una proporción bastante elevada en la totalidad de los escenarios parisinos. Es importante añadir que, en nuestra relación, solo hemos incluido escenarios de París y no los de la Grande Couronne, con la excepción de unos teatros cuyos espectáculos entraban en la programación de festivales teatrales de la capital francesa. Existe una gran disparidad entre unos escenarios y otros tanto por su tamaño como por su renombre. Así, se pudo apreciar el teatro español en escenarios pequeños como el Théâtre de La Loge (80 butacas) y en salas más importantes como el Théâtre de la ville (1000 butacas) o en la sala Richelieu de la prestigiosa Comédie Française y su capacidad para 862 espectadores.

Dentro de los escenarios que más teatro español han recibido, podemos destacar principalmente a dos: el Théâtre 13 que fue el escenario con más representaciones de obras españolas (84 representaciones de 5 espectáculos distintos) y el Café de la Danse que programó 12 espectáculos distintos. El primero que fue creado en 1981, se encuentra en el $13^{\circ}$ arrondissement de la capital y consta de dos salas de 250 y 224 butacas. El segundo ubicado en el $11^{\circ}$ arrondissement fue inaugurado en 1992 y tiene 
una capacidad para 499 espectadores. La razón por la cual el Café de la Danse representó mucho teatro español es porque es la principal sede del festival Don Quijote.

\subsubsection{El festival Don Quijote}

El festival Don Quijote es la gran cita anual del teatro en español de la capital francesa. Creado en 1992 propone a los espectadores descubrir la cultura teatral española e hispanoamericana en versión original, ya que la casi totalidad de las obras están representadas en español sobretituladas o no en francés. El festival fue el resultado de la iniciativa del grupo Zorongo, una compañía fundada en 1989 con el objetivo de difundir la cultura teatral hispánica. La crítica suele valorar la tarea de selección de espectáculos de Zorongo cuya "pericia se funda en un conocimiento fino de la escena hispánica"42 (Santi, 2015). Así, el festival se otorgó "una misión de servicio público del teatro hispánico"43 (Robert, 2015). El grupo nos informa que tras 24 años de existencia, el festival ya recibió 236 producciones, alrededor de 2000 profesionales del sector y acogió a más de 85.000 espectadores ${ }^{44}$. Incluso los organizadores se orgullecen de haber recibido producciones de todas las Comunidades Autónomas españolas. Su labor de difusión del teatro español fue reconocida en el 2011, año en que recibió el premio Max de la crítica en España. Por fin es importante añadir que el festival solamente programa obras que nunca han sido representadas en París.

\subsection{LOS AUTORES ESPAÑOLES REPRESENTADOS}

Gráfico1: Los principales autores españoles representados en París en 2014 y 2015.

Los principales autores españoles representados en París en 2014 y 2015

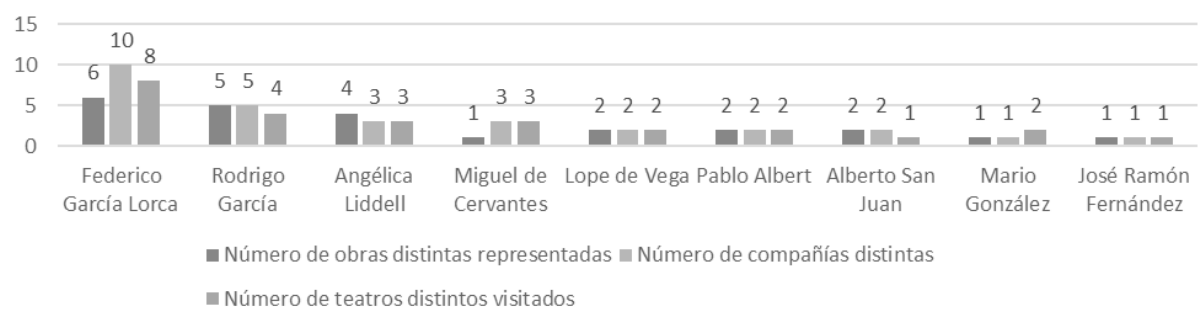

42 "Dont l'expertise se fonde sur une connaissance fine de la scène hispanique".

43 "Mission de service public du théâtre hispanique".

44 Puede consultarse la página oficial del festival Don Quijote: $h$ ttp://festivaldonquijote.fr/ [03/04/2016]. 


\subsubsection{Los autores del Siglo de Oro}

El autor español del siglo de Oro más presente en nuestro periodo de estudio fue Miguel de Cervantes. En efecto, Cervantes aparece lógicamente en esta lista por ser el autor de la obra maestra de la literatura española: El Ingenioso hidalgo Don Quijote de la Mancha. De hecho, a pesar de haber sido dramaturgo en su tiempo, todas las representaciones que se hicieron de Cervantes en París han sido adaptaciones del Quijote y no de sus obras teatrales. Se asocia esencialmente el nombre de este autor con el de su famoso protagonista y es por esta razón que el festival de teatro hispano de París lleva su nombre a pesar de no tratarse de una obra de teatro. En nuestro periodo de estudio, tres espectáculos fueron adaptados de Miguel de Cervantes. Dos eran adaptaciones de El Ingenioso hidalgo Don Quijote de la Mancha: una adapatacion de Régis Hébette interpretada por la Compañía Public Chéri y representada doce veces en septiembre de 2014 en el Théâtre de L'Echangeur y otra por Laurent Rogero, interpretada por la compañía Anamorphose, representada el 4 de diciembre del mismo año en el théâtre de I'Agora. Otro espectáculo en la primavera 2014, Ignatius, des idiots et des fous, de Chantal Mélior, se inspiró en el personaje del Quijote, tratando la obra del tema de la locura.

En nuestro periodo de estudio, dos obras Lope de Vega han sido representadas en París. La primera fue una adaptación de Fuenteovejuna por la compañía catalana Obskené en el Café de la danse el 25 de noviembre. Esa versión fue una adaptación de la obra al estilo de teatro de calle. La segunda obra adaptada de Lope fue La discreta enamorada por la compañía Soy Creation. Se puede destacar la longevidad de este espectáculo porque fue representado treinta y seis veces en el Théatre 13 entre marzo y abril 2015 y siguió programada en el año 2016. Esta puesta en escena fue nominada dos veces a los premios Molières 2015, los premios más importantes del teatro en Francia.

Entre el 14 y 19 de abril de 2015 se representó el espectáculo Don Juan, amère Mémoire de moi, de Miguel Gallardo y Paco Bernal e interpretado por la compañía Pelmânec. Este espectáculo de títeres se inspiró en varios autores que tenían a Don Juan como protagonista empezando por Tirso de Molina, el autor de la primera obra que introdujo este personaje: El Burlador de Sevilla.

En el marco del festival Don Quijote 2014, un espectáculo de entremeses de burla fue programado en el Café de la Danse. Este espectáculo representaba entremeses de autores clásicos como de Avellaneda, Calderón de da Barca, Quiñones de Benavente y de la Hoz. Así, el público francés pudo descubrir esa lista de autores españoles clásicos poco conocidos en el Hexágono con la excepción de Calderón.

El 26 de noviembre 2015 se representó La Celestina, de Fernando de Rojas, en el Café de la Danse. Adaptado por Ricardo Iniesta e interpretado por la compañía Atalaya, este 
espectáculo tenía como propuesta modernizar la obra de Rojas tanto lexicalmente como estéticamente acercándola así al público de hoy en día.

\subsubsection{Autores del siglo XIX y XX}

El autor granadino Federico García Lorca, representado por primera vez en París en 1938 (Torres Monreal, 1992) fue de lejos el autor más representado en los escenarios parisinos en nuestro periodo de estudio. Seis de sus obras fueron representadas por diez compañías en ocho escenarios distintos. También fue el autor con el número más elevado de representaciones. En efecto, se pudo contabilizar un total de 141 representaciones de espectáculos adaptados del autor granadino. Su obra, La casa de Bernarda Alba fue la más adaptada porque inspiró a seis espectáculos diferentes cuya suma total de las representaciones se elevaba a 79, es decir, la mitad de todas las representaciones adaptadas de Lorca. Se pueden destacar las 55 representaciones en el 2015 de su adaptación por la compañía de La Comédie Française. Esa compañía francesa suele representar pocas veces a autores extranjeros excepto grandes nombres del teatro mundial lo que significa que en Francia Federico García Lorca está considerado como uno de los dramaturgos más importantes de la historia. Otra particularidad que podemos observar, es la panoplia de géneros que han sido representados. Porque se pudo ver tanto dramas del autor (La casa de Bernarda Alba, Bodas de sangre, Yerma) como sus comedias y obritas para títeres o guiñoles (El retablillo de Don Cristóbal, Amor de don Perlimplín con Belisa en su jardín), además de una adaptación totalmente libre de la compañía Ditirambo que representó La casa de Bernarda Alba de manera grotesca, siendo los personajes femeninos interpretados por hombres. Por fin, se realizó una lectura dramatizada en la Maison de la Poésie de Juego y teoría del Duende, una conferencia que Lorca pronuncio en 1933 en Buenos Aires y La Habana. El tema principal de esta obra es el Duende, una interpretación típicamente andaluza del baile y de la tauromaquia.

El día 23 de noviembre de 2014, el autor-actor Alberto San Juan interpretó la obra Todo dice que sí... en el Café de la danse. Este espectáculo consistía en una lectura dramatizada de poesías de autores españoles del siglo XX: Jiménez, Salinas, Celaya, Cernuda, Jaime Gil de Biedma, Goytisolo, González y Fonollosa.

Durante la primavera 2015 se representó veinticuatro veces el espectáculo Elise ou la vraie vie, una adaptación de la novela de Claire Etcherelli, por la española Eva Castro. Esa obra trataba de la difícil existencia de una mujer obrera enamorada de un hombre argelino durante los años 50, en plena Guerra de Argelia.

El 26 de abril de 2015, se escenificó un espectáculo de títeres dedicado al personaje de Don Juan en el Théâtre 13. Esta creación estuvo inspirada en varios autores que utilizaron este personaje incluyendo dos autores españoles: Tirso de Molina y Josep Palau i Fabre. El 
autor catalán que pasó una parte de su vida en París, fue el único autor contemporáneo dentro de los autores explotados para este espectáculo. Porque Palau i Fabre dedicó buena parte de su obra al personaje de Don Juan escribiendo un ciclo exclusivamente dedicado a este personaje.

\subsubsection{Autores contemporáneos}

El dramaturgo argentino-español Rodrigo García (nacido en Argentina y que llegó a Madrid en los años ochenta donde fundó su propia compañía) fue el segundo dramaturgo de nacionalidad española más representado en París. Cinco de sus obras visitaron los escenarios de la capital francesa. Tras una carrera en España, se convirtió en director del centro dramático de Montpellier. El escenario de la capital que García y sus obras suelen visitar es el Théâtre du Rond-Point. En 2014-2015, se representaron dos de sus obras en este escenario: Lo bueno de los animales es que te quieren sin preguntar nada, en enero y febrero de 2015 (una adaptación de Christophe Perton e interpretación de la compañía Scènes \& Cités) y Daisy, en marzo de 2015, representada por la compañía La Carnicería Teatro que fundó en 1989. La otras obras de Rodrigo García representadas en París fueron Jardinería Humana en el teatro de Verre, adaptada por Patrick Piard e interpretada por la compañía Graine de Soleil en marzo de 2014; Notas de cocina, adaptada por Jean-Luc Vincent e interpretada por la compañía Les Roches Blanches, en el teatro de la Loge en octubre de 2015 y la obra 4 con la puesta en escena del propio autor con su compañía la Carniceria Teatro, rebautizada HTH en noviembre de 2015 en el teatro Nanterre-Les Amandiers

La dramaturga catalana Angélica Liddell pertenece al grupo de dramaturgos españoles más presente en Francia hoy en día. Desde su estreno en los escenarios parisinos en el 2005, Liddell y sus obras no han parado de recorrer el Hexágono difundiendo su teatro vanguardista y muy politizado. Estos últimos años, sus creaciones empezaron a frecuentar el Théâtre de L'Odéon-Théâtre de l'Europe, un teatro que hace más de tres décadas empezó a especializarse en acoger espectáculos vanguardistas de toda Europa. Así, en 2014, su obra You are my destiny fue representada por la compañía Atra Bilis. En 2015, esta compañía, que la dramaturga fundó en 1993, llegó al Odeón con Primera carta de San Pablo a los Corintios. Lo que se puede destacar del teatro de Liddell es el lado universal de su teatro porque sus puestas en escena están llenas de elementos de culturas distintas como cantantes ucranianos en You are my destiny, además de presentar una parte de la obra en italiano. En Primera carta de San Pablo a los Corintios es el idioma sueco el que introdujo en su creación. Es importante añadir que no solamente Liddell ha traído sus creaciones a la capital francesa, sino que también dos de sus obras han sido 
adaptadas por compañías francesas Belgrado y $Y$ los peces salieron a combatir contra los hombres, respectivamente, en mayo de 2014 y diciembre de 2015.

El 26 de mayo de 2014, se pudo ver en París una pieza de Mónica Almirall, Miquel Segovia y Albert Pérez Hidalgo de la compañía Atresbandes. En este espectáculo, el público asistió a una comida entre amigos, en la cual aparece un conflicto que hizo surgir el miedo de los personajes, un sentimiento que inspiró el título de la pieza: Solfatara (la apertura de donde salen los vapores en un terreno volcánico).

La compañía los Torreznos, compuesta por Rafael Lamata y Jaime Vallaure y especializada en trabajos que representan la cotidianeidad, representó en París dos de sus creaciones: La noche electoral y 35 minutos, el 11 de junio de 2014, en el Théâtre de la Ville. 35 minutos, el primero de los dos espectáculos tenía como tema principal el paso del tiempo. Para ilustrarlo, los actores contaban de 1 a 2.100, una cifra que corresponde al número de segundos que contienen 35 minutos. El segundo, La noche electoral, tenía como tema principal el poder y en este se pudo ver a los actores todavía sentados enumerando nombres de grandes personalidades políticas y sociales del siglo XX.

En junio de 2014, se representó el espectáculo Caprices, de José Drevon. Esta obra fue inspirada en los grabados de Francisco de Goya. Drevon trató de descifrar las obras del pintor, de asociarlas a palabras y de darles voz a través de la actuación de un actor.

El 16 de junio de 2014, la obra Materia Prima, de Pablo Fidalgo y la compañía La Tristura, se representó en el Café de la Danse. En esa obra se pudo ver en el escenario la evolución de varios personajes a través de su educación (Materia Prima pertenece a una Trilogía de la Educación de la compañía).

El 28 de junio de 2014 en el théâtre de la Ville se programó la obra Public Domain del catalán Roger Bernat, un autor especializado en crear un teatro participativo donde suele tratar temas político-sociales. Así, este espectáculo consistía en reunir al público en una plaza y darle instrucciones a través de auriculares para orientarlo hasta que se formaran grupos de personas que se juntaban por afinidades sociales comunes.

Entre el 5 de julio y el 23 de noviembre de 2014, la compañía del théâtre de l'Opprimé representó la obra Remarquables Utopies de un texto colectivo incluyendo al dramaturgo español José Ramón Fernández. Esa pieza tenía como tema principal la utopía. Ambientada en el siglo XIX, estaba protagonizada por un grupo de anarquistas italianos que se dirigían a Brasil, creando un choque cultural entre una sociedad europea libertaria y otra que acababa de salir de la monarquía y de la esclavitud.

A lo largo de los años 2014 y 2015, se representó la comedia Picnic en el campo de batalla, de Fernando Arrabal, interpretada por la compañía del Café de la Gare. Muy cercano a los grupos del surrealismo en los años 50, el autor melillense vive en Francia desde esta década. El autor quiso denunciar la Guerra Civil a través de esta obra donde una pareja decide visitar a su hijo soldado en el frente e ir de picnic con él en el campo. 
El 16 de octubre de 2014 se programó una lectura dramatizada de Todo es silencio, de Manuel Rivas en la Maison de la Poésie. Esa obra, cuya historia se ubicaba en Galicia, tenía como tema principal los conflictos generacionales. A través de un conflicto entre jóvenes traficantes de droga y agentes de policía mayores, se pudo ver la visión distinta del mundo que existía entre las nuevas y antiguas generaciones.

El 21 de noviembre de 2014 y 24 de noviembre de 2015 se representó Escenas para una conversación después del visionado de una película de Michael Haneke, de Pablo Gisbert respectivamente en los teatros Ouvert y Bastille. Esa función compuesta de doce historias (y acompañada de una puesta en escena enriquecida por alternancias entre diálogos, proyección de textos y música electrónica) pretendía describir la sociedad urbana y capitalista de hoy examinando los traumatismos que puede causar.

El 23 de noviembre de 2014 después de la lectura de Todo dice que sí..., Alberto San Juan, galardón del premio Max de Teatro Alternativo, representó su creación, Auto retrato de un joven capitalista español. Se trataba de un monólogo en el que criticaba los abusos de la sociedad capitalista contemporánea.

La obra Penal de Ocaña, de María Josefa Canellada, fue representada en el Café de la Danse el 26 de noviembre de 2014. Este espectáculo fue una adaptación del diario de la asturiana, estudiante de letras durante la Guerra Civil y que nos dio su testimonio sobre el conflicto cuando trabajaba como enfermera voluntaria.

El autor salamantino Jaime Santos con su compañía La Chana Teatro representó el 4 de diciembre, en el Espace Beaujon, una adaptación de la obra anónima El Lazarillo de Tormes con una puesta en escena basada en el Teatro de objetos donde estos fueron tan protagonistas como los personajes en el escenario.

El 6 de diciembre de 2014 se representó en el Café de la Danse El Régimen del pienso, de Eusebio Calonge y la compañía La Zaranda. Esa obra trataba de la condición humana que en el escenario aparecía no muy distinta de la de los animales cuando un virus causado por el pienso en la industria porcina hizo entrar a la empresa en crisis. A partir de ahí, los empleados tenían que luchar para salvar su puesto de trabajo.

Una adaptación de la novela el Largo viaje, de Jorge Semprún, se representó el día 6 de febrero de 2015 en Théâtre de l'Ouest Parisien. Con una adaptación de Pascal y Vincent Reverte, el espectáculo estaba ambientado en un vagón con detenidos que tenía como destino el campo de Buchenwald. Durante este viaje, los personajes describían su visión del pasado y del futuro.

El 7 de febrero de 2015, en la Maison de la Poésie, se realizó una lectura dramatizada de La ridícula idea de no volver a verte, de Rosa Montero. La obra de la periodista y escritora madrileña trató del tema de la pérdida de un ser querido. Para ilustrar esa ausencia, utilizó un fragmento del diario de Marie Curie, en el cual contaba el vacío sentido por la ausencia 
de su marido. Rosa Montero describió una situación que ella misma experimentó y en la cual la mayoría de la gente se podía identificar.

El 5 de mayo de 2015 se representó la obra House in Asia, de Alex Serrano y Pau Palacios. Este espectáculo que fue representado en el marco de un festival de arte del títere, representaba el día del asalto de Ossama Ben Laden, en Pakistán, a través de maquetas y proyecciones de vídeos.

El 6 de mayo de 2015, se realizó una lectura dramatizada de la obra También esto pasará, de Milena Busquets, con ocasión de su estreno en Francia en mayo de 2015. La obra de la escritora catalana contaba cómo una mujer rememora los recuerdos de su pasado cuando vuelve a la casa de verano de su infancia.

El 21 de noviembre de 2015 fue programada la obra Famélica, de Juan Mayorga, en el Café de la Danse. Esa comedia adaptada por Jorge Sánchez e interpretada por la compañía La Cantera tenía como contexto el ámbito laboral y pretendía revelar todos los vicios que ese mundo contiene.

La obra Juana, la reina que no quiso reinar, representada por la compañía Histrión Teatro, estuvo programada el día 23 de noviembre de 2015. A través de un monólogo, ese drama trataba el destino de mujer y de la desesperación de Juana, la reina que fue confinada para no llegar al trono.

Una representación del cuento La niña, del autor Aragonés Grassa Toro, fue programada el día 24 de noviembre de 2015 en el Café de la Danse. Adaptada por Rosa Díaz para un público juvenil, cuenta la historia de una mujer que ve a una niña en una botella en el agua. Tras haberla perdido de vista, va en su búsqueda, simbolizando así la búsqueda de la niña que hay en ella.

El drama Ligeros de equipaje, del autor aragonés Jesús Arbués y su compañía Viridiana, fue programado en el Café de la Danse el 24 de noviembre de 2015. A través de una adaptación de testimonios reales, este espectáculo trataba de la condición de los refugiados españoles de la Guerra Civil en el sur de Francia en 1939.

El 27 de noviembre de 2015 se programó Només són dones, de la catalana Carmen Domingo con una adaptación de Carme Portaceli y su compañía Factoría Escénica Internacional. Único espectáculo en catalán de nuestra relación. La obra trataba de la vida de las mujeres durante la Guerra Civil a través de la lucha de cinco mujeres que vivían en este periodo (esos cinco personajes siendo interpretados por una sola actriz).

Nacida en Barcelona y viviendo en Francia desde hace varias décadas, Roser Montilló Guberna representó su obra Coûte que coûte, el 27 de diciembre de 2015, en el Théâtre National Chaillot Esa comedia trataba de la dualidad de la existencia entre la felicidad y la desdicha con una puesta en escena que conciliaba la música, el canto y el baile, teniendo la catalana una formación en todas esas disciplinas. 


\subsection{LAS COMPAÑIIAS ESPAÑOLAS PRESENTES EN LOS ESCENARIOS DE PARÍS}

El número de compañías españolas que trabajaron en París en 2014 y 2015 ha sido de 19. La mayoría de ellas (11), visitaron los escenarios parisinos con ocasión del festival Don Quijote y tres lo hicieron para el festival Chantier d'Europe. Esa cifra muestra que no es muy común ver a una compañía española trabajar en París fuera de un evento dedicado especialmente a la apertura de la programación a obras extranjeras. De hecho, solo la compañía Atra Bilis visitó dos veces un escenario de París (el Odéon).

Buena parte de las compañías españolas provenían de Cataluña, posiblemente dado el hecho de que, además de la cercanía geográfica, la escena catalana es muy abierta a nuevas creaciones vanguardistas y alternativas contrariamente a la de Madrid que, según Rodrigo García suele ser más convencional. Para ilustrarlo, el dramaturgo dijo: "Madrid es la única ciudad donde me han despreciado siempre, pateando en la sala y gritando insultos en todas y cada una de mis obras" (Cuesta, 2015) y opinó también que en España existe una "tendencia al conservadurismo" (Romo, 2015). De la misma manera, tras el triunfo que conoció en París, Angélica Liddel decidió renunciar a la escena española afirmando: "Por primera vez en mi vida, he conocido el respeto estando en el extranjero" (Vicente, 2014). El exilio de esos dos dramaturgos vanguardistas a Francia demuestra que la escena parisina está dispuesta a recibir creaciones alternativas del extranjero.

Tabla 2. Relación de las compañías españolas en París en 2014-2015 (por orden alfabético)

\begin{tabular}{|l|l|l|}
\hline & Nombre de la compañía & Origen \\
\hline 1 & Atalaya & Andalucía \\
\hline 2 & Atra Bilis Teatro & Madrid \\
\hline 4 & Atresbandes & Cataluña \\
\hline 5 & Agrupación Señor Serrano & Cataluña \\
\hline 6 & El Conde de Torrefield & Cataluña \\
\hline 7 & Factoria Escènica Internacional & Cataluña \\
\hline 8 & Histrión Teatro & Andalucía \\
\hline 9 & La Carnicería/HTH & Madrid \\
\hline 10 & La Cantera & Castilla la Mancha \\
\hline 11 & La Chana & Castilla y León \\
\hline 12 & Obskené & Cataluña \\
\hline 13 & Nao D'Amores & Madrid \\
\hline 14 & La Mekánica & Cataluña \\
\hline
\end{tabular}




\begin{tabular}{|l|l|l|}
\hline & Nombre de la compañía & Origen \\
\hline 15 & La Tristura & Madrid \\
\hline 16 & La Zaranda & Andalucía \\
\hline 17 & Los Torreznos & Madrid \\
\hline 18 & Teatro Corsario & Castilla y León \\
\hline 19 & Viridiana & Aragón \\
\hline
\end{tabular}

\section{REFERENCIAS BIBLIOGRÁFICAS}

CHASLES, P. (1847/ reimpresión 1973). Études sur l'Espagne et sur les influences de la littérature espagnole en France et en Italie. Genève: Slatkine.

CIONARESCU, A. (1983). Le masque et le visage : du baroque espagnol au classicisme français. Ginebra: Droz.

COUDERC, C. (2012). Le théâtre espagnol du Siècle d'Or en France. De la traduction au transfert culturel. Christophe Couderc (dir.). Nanterre: Presse universitaire de París Ouest.

CUESTA, I. (2015). "Rodrigo García: En Madrid me han despreciado siempre". El País, 29/05 (también en: http://ccaa.elpais.com/ccaa/2015/05/28/madrid/1432829259_944255.htm/ [28/03/2016]).

MARTINENCHE, E. (1906). La Comedia espagnole en France de Hardy à Racine. París: Hachette (también en https://archive.org/details/lacomediaespagno00martuoft [24/11/2016]).

(1906). Molière et le Théâtre Espagnol. Paris: Hachette. (también en http://gallica.bnf.fr/ ark:/12148/bpt6k9611223j.r=martinenche?rk=42918;4 [24/11/2016]).

MINISTÈRE DE LA CULTURE ET DE LA COMMUNICATION (2013). "Chiffres clé 2013, Statistique de la culture". Théâtre et Spectacle. París (también en: http://www.culturecommunication. gouv.fr/content/download/62896/481991/file/Chiffres\%20cl\%C3\%A9s\%202013_ Th\%C3\%A9\%C3\%A2tre\%20et\%20spectacles.pdf [15/02/2016]).

PICCIOLA, L. (2002). Corneille et la dramaturgie espagnole. Tübingen: Gunter Narr Verlag.

ROBERT, C. (2015). "23ème Festival Don Quijote", Journal La Terrasse (28/10/2014), 225 (también en $h t t p: / / w w w . j o u r n a l-l a t e r r a s s e . f r / 23 e m e-f e s t i v a l-d o n-q u i j o t e[28 / 03 / 2016])$.

ROMERA CASTILLO, J. (2011). Pautas para la investigación del teatro español y sus puestas en escena. Madrid: UNED.

(2012a). "Teatro en escena: un centro de investigación sobre la vida teatral en España". Teatro de Palabras (Université de Québec a Trois-Rivières, Canadá) 6, 175201 (en línea: http://www.uqtr.ca/teatro/teapal/TeaPalNum06Rep/TeaPal06Romera.pdf [15/02/2016]). 
(2012b). "Estudio del teatro en la primera década del siglo XXI en el SELITEN@T". Don Galán 2 (también en: http://teatro.es/contenidos/donGalan/donGalanNum2/pagina. php?\%20vol=2\&\%20doc=1_5[15/02/2016].

ROMO, J. L. (2015). "Rodrigo García: «Me alejé de España con dolor y rabia»". El Mundo (12/06/2015) (también en: http://www.elmundo.es/madrid/2015/06/12/ 5579ecc546163ff9648b4598.html [28/03/2016]).

SANTI, A. (2015). "Festival Quijote 2015". La Terrasse, 237 (octubre) (también en: http://www. journal-laterrasse.fr/wp-content/uploads/2015/11/la_terrasse_237 1.pdf[15/02/2016]). TOQUERO, C. (2002). “Un lenguaje sin fronteras para el teatro del siglo XXI”. En El teatro español ante el siglo XXI, César Oliva (ed.), 111-115. Madrid: Sociedad Estatal España Nuevo Milenio. TORRES MONREAL, F. (1992). "La recepción del teatro de Lorca en París (1938-1955)". En Federico García Lorca: Perfiles críticos, A. Rodríguez López-Vázquez y K. Reichenberger (ds.), 33-38. Kassel: Reichenberger.

VICENTE, A. (2014). "La directora Angélica Liddell renuncia a la escena española". El País, 14/12 (también en: http://economia.elpais.com/economia/2014/12/13/ actualidad/1418480562_341275.html [08/04/2016]).

WALLON, E. (2010). "Le spectacle vivant en Chiffre". En Politiques et pratiques de la culture, 128135. París: La documentation française (también en: http://e.wallon.free.fr/IMG/doc/Notice9Theatre_chiffres_.pdf [15/02/2016].

Recibido el 1 de mayo de 2016.

Aceptado el 25 de noviembre de 2016. 
